\title{
Pursuing Concordance: Moving Away from Paternalism
}

\author{
John McKinnon \\ Senior Lecturer in Nursing \\ School of Health and Social Care \\ University of Lincoln \\ Brayford Pool \\ Lincoln LN6 7TS
}

Email (work) jmckinnon@lincoln.ac.uk

(home) john.mckinnon100@gmail.com

Telephone: Mobile 07905505282

Work 01522886024

Home 01790754581 


\title{
Pursuing Concordance: Moving Away from Paternalism
}

\begin{abstract}
In the second of two papers exploring the value and application of concordance across nursing practice the discussion is aimed at clinical settings and patient groups where concordance may have been viewed as impractical. The author harnesses Cribb and Entwhistle's broader conception of shared decision making and the notion of decision making capacity as a continuum to argue that concordance can be pursued effectively in challenging settings such as childcare practice, mental health and the care of older people. As in the first paper the discussion is not limited to medicines management but remains engaged with all aspects of nursing practice. Legal and ethical Frameworks, social participation theory and research across health care practice are sourced to argue for concordant approaches in the care of patients who may at times have compromised decision making capacity. Ideas of direct and indirect concordance are explored.
\end{abstract}

Key Words: Concordance; Shared Decision Making; Participation ; Mental Health ; Children; Older People

\section{Introduction}

Concordance in healthcare is a partnership of equals on which shared decision making and care planning are built (McKinnon, 2013). The root values of the concept can be traced to the World Health Organization (WHO, 1986) Ottawa Convention which established the right of every person to participate in their own health care.

However in clinical settings which serve children or those whose decision making capacity is perceived as compromised a concordant approach may seem impractical. But negative claims about the viability of concordance with a given patient group cannot be taken at face value. In their report for the Kings Fund Institute Coulter and Collins (2011) stated that many of the arguments tabled by practitioners as to why concordance was not feasible in their practice were not founded in evidence. Such views may be associated with process driven task orientated practice where perspectives on consent and decision making are rigid. This may be strongly related 
to the need for professionals to retain power over their patient group. In such a context little time or effort is invested in the art of negotiation pitched at the appropriate level and setting (Simmons, Hetrick and Jorm, 2010).

Duty to care and the right of a patient to self determination are not irreconcilable unless we assert that practitioners have a monopoly on beneficence. Concerns raised about the dangers of concordance share a common assumption albeit one based on sincere motives: the practitioner always knows best and that failure on the part of a patient to acknowledge this could be harmful to them. For example the term 'patient preference' is often used in place of 'patient expertise' inferring that service users do not exercise proper judgement based on sound self knowledge (Cribb and Entwhistle, 2011). Shared decision making is disingenuous unless we acknowledge that while patients may often make the right decisions they also have the right to make what we believe to be the wrong ones and live with the consequences.

Nineteenth century philosopher John Stuart Mill (1859:1:6) expressed the proper relationship between personal autonomy and paternalism in the following way:

"The only purpose for which power can be rightfully exercised over any member of a civilized community, against his will, is to prevent harm to others. His own good, either physical or moral, is not sufficient warrant."

It is noteworthy that in legislation governing decisions with children and those whose decision making may be compromised (DH, 1989, 2001; 2004; Office of Public Guardian, 2007) emphasis is placed not on barriers and precautions but on the 
potential to engage with the wishes of the individual and represent their will in care planning wherever possible.

That there is a way with concordance where there is a will in challenging settings is demonstrated by Bowskill and Garner (2012) who found in practice that patients with low health literacy can sustain better medicine regimens when practitioners use a range of simple techniques. These techniques include speaking slowly, using simple language free of professional terminology, repeating information and teach back techniques.

Cribb and Entwhistle (2011) raise two points which are crucial to an exploration of concordance in any setting where difficulties with decision making capacity exist.

1. Decision making capacity is a continuum across the lifespan for all patients. Preferences values and beliefs which are unstable or contradictory compete for primacy in a hierarchical model of thinking and choice. Even in the presence of clear evidence patients will often struggle to make decisions, fearing the consequences of error. They may have their judgement and perception clouded by a range of social, cultural, commercial and political influences. Reflection on decisions in the light of unforeseen occurrence may cause patients to feel regret leading them to suspend or reverse their decisions. Competence to participate is not a static concept. At different points in life we all require more or less help with decisions but the right to own our decisions together with the resultant success or failure should whenever possible be ours.

2. There are narrow and broad conceptions of concordance. In the former care is planned on the basis of a combination of evidence base and patient 
preference. In the broad conception concordance takes the shape of an open ended relationship. In this relationship the patient's autonomy and personhood remain paramount and options are viewed in the light of best evidence. However the practitioner is permitted to sensitively challenge and promote revaluation of the patients valued opinions, judgements, choices and decisions. Within this relationship of trust and mutual respect plans and the values which underpin them can be revisited without loss of face on either part. Equally plans which have been negotiated when the patient enjoyed 'best health' can be implemented when the patient lacks decision making capacity.

It is within this broader perspective on concordance that new possibilities can be opened up in areas of practice which appear challenging. As in the first paper, this paper applies such a broad perspective across all nursing practice on the basis that medicine taking is only part of the patient's 'whole life' experience in which the nurse must seek to work. Below evidence relating to the application of concordance to child health care, older people and mental health is discussed. Throughout the discussion I also espouse Entwhistle and Cribb's argument (2011) that an varying level of decision making capacity is the rule rather than the exception throughout life. I am aware that other challenging settings exist outside these clinical areas but I would argue that the principles arising from the discussion that follows are translatable and therefore applicable elsewhere.

\section{Concordance and Children}

The notion of working in partnership with children in healthcare calls for some honest reflection on the part of practitioners. The tendency among adults to 
minimize, undervalue and overlook the views and feelings of children for many deeply rooted historical social and religious reasons has been well documented (Leach, 2000; Mason and Fattore (eds), 2006). It follows that the potential for children to participate in their care does not necessarily concur with the related values harboured by individuals and within communities of practice (Webb, 2004).

There is a need to untangle the reality of what children are capable of deciding from our own assumptions and prejudices regarding how we expect them to behave. At every level of her model of participation (figure 1) Shier (2001) challenges the willingness of practitioners to listen and engage with children as reasoning agents with views and plans of their own. Shier argues that opportunities for child involvement and effective policies crafted to allow them are only possible when professionals are committed to child centred values. Child participation in healthcare can hardly be expected to occur automatically in communities of practice where practitioners are still struggling to effectively involve adults in decision making (McKinnon, 2013) nor can a child's reticence be taken as a sign of a lack of decision making capacity given these restraining social and structural circumstances. Williams and Noyes (2009) point out that within the current legal framework children are not always deemed capable of understanding all the issues relating to their care. However they add that this is often due to a lack of explanatory material with content which is easy for a child to understand.

In Britain, children's rights legislation (Children Act 1989) stipulates that while the extent of autonomy afforded to children should be commensurate with their development, their active involvement in decisions which affect them should be encouraged as early in life as possible. The law is weighted to permit maximum 
possible child involvement in line with article 12 of the UN Convention of the Rights of the Child (1989). This is observable in the fact the parents may overrule child refusal to treatment but they may not overrule the consent of a child where it can be determined that the child fully understands the clinical situation and is making an informed choice (DH, 2001). This is called the 'Fraser' or 'Gillick' principle. Beyond issues of consent there are issues of cooperation. Children are increasingly being asked to take responsibility for medicine taking especially within school hours. Such cooperation requires sound explanation and concordance through accommodation of the child's meanings and concerns (Williams and Noyes, 2009).

There is a growing body of knowledge (Tates et al, 2002; Sanz, 2003; Gabe et al, 2004; Kilkelly and Donnelly, 2006; Save the Children, 2009; Williams et al, 2011) as to children's cognitive and social abilities in a healthcare setting. Children are able to grasp the rationale for treatment of a disease process earlier than one for a preventative measure such as immunisation. Children of primary school age have also been shown to be conversant with their respective conditions and autonomous with their medicines. Unlike adults children's concerns are more likely to surround the pain discomfort, side effects and stigma among their peers furnished by treatment than by the long term side effects. The imaginative use of models sketches and conversation pitched at the appropriate level of understanding has led to the active involvement of children much younger than seven years of age in care planning (Gabe et al, 2004). Furthermore the use of music and songs have been shown to be effective in imparting principles of healthy living to preschool children (Save the Children, 2009). However the pattern of adherence to such progressive practices is a chequered one. 
Sanz (2003) notes that traditional paediatric consultations have confined interaction with the child to pleasantries and clinical examination and concentrated the discussion of care plans with the parent. However she also notes that children in their preschool years have been heard to interrupt and correct their parent's narrative of the child's health experience. This suggests a personally held knowledge of health state and a potential for greater participation. Although the willingness of parents to encourage their child's involvement in a consultation may vary they have been shown to interfere in practitioner -child interaction for fear that their own views and executive decision making role may be undermined (Tates et al, 2002). In a study of fifty one children and their parents in the Republic of Ireland through interviews and focus groups, Kilkelly and Donnelly (2006) found that children had mixed experiences of the health care system. Consultations with nurses and dentists yielded the most positive reports of conversation and specific explanations pitched at a level that young patients could understand. However many clinical procedures and investigations were not explained. Most children had experienced situations in which practitioners spoke either exclusively to their parents or addressed them and their parents together. The study demonstrated that children hold strong views on what they want from the healthcare system. Exclusion from conversation caused deep and widespread resentment among children. Such exclusion also caused children to worry that their conditions were more serious than had been disclosed to them. There was a consensus that they were better placed than their parents to discuss their symptoms and a desire to have a greater share in decision making. It is interesting that the latter point was tempered by realism in that many children acknowledged that some situations offer no viable options and trusted the judgement of informed others in such circumstances. Children wanted explanations in appropriate language as to the principled and practical rationale for their care. The 
use of toys and games for distraction and the use of toys, models, pictures, sketches, stories and songs to explain clinical practice together with personalised names for clinical equipment such as 'Freddy' the cannula were highly valued. Like adult groups, the children in this study identified a trustworthy relationship with an approachable sympathetic and good humoured practitioner as crucial to good care. These findings have largely been endorsed in the United Kingdom by the Final Report of Children's Information Matters Project (Williams et al, 2011) which stated that the potential for child participation in healthcare has still to be optimised. The project team called for the development of clinical pathways to facilitate standardised shared decision making with children, an expansion in child friendly information including that provided in medicine packs by pharmaceutical companies and health information available on the internet.

The data collected from children in Kilkelly and Donnellly's work (2006) presents a formidable challenge to practitioners when compared with the data collected from parents. While a minority of parents welcomed a concordant approach by professionals toward their children, most were wary of it. Parents shared their childrens' views on the importance of explanations, play and child friendly personalities among practitioners. However they believed that as adult carers they were in the best position to judge the amount and level of information their child could absorb. On this basis parents saw themselves as gate keepers; able to limit the extent of their children's participation and protect against the anxiety and stress caused by excessive information. It seems in the light of these findings that while young children can and should be involved in discussions about their care, there is a danger that their parents may be alienated in the process (Williams et al, 2011). McklinDon and Schlucter (2004) describe a triangular partnership between a nurse a 
child and a parent which is child focused but employ and value the parent's skills as mentor, interpreter, teacher and exemplar. As the child approaches adolescence and then adulthood the level of negotiation with parents gradually diminishes as the autonomy of a young person develops. Treseder's model of participation (2004) favours this evolving approach [Figure Two]. Rather than viewing forms of participation in a hierarchical way, he argues that the age, emotional and cognitive maturity of the individual child together with the complexity of the decision at hand will dictate the amount of help a child or young person requires in a given situation.

In this vision of partnership working concordance becomes a relationship of three rather than two but where the voice of the child as the patient was highly valued. We might describe this approach as moving between direct concordance (between practitioner and patient alone) and indirect concordance where family members play a part in clarifying and informing on the patient perspective and wishes. This sets a fine example for other areas of practice.

\section{Concordance and Older People}

The social construction of old age as a time of diminishing health and ability has led some to believe that older people should not be left to make decisions about their healthcare (McCormack, 2003). In reality there is very little evidence to support this. In a critique of the application of concordance to the care of people in old age, Snowden (2008) cites Neame and colleagues' study (2005) of patients with rheumatoid arthritis which showed that $22 \%$ of older adults believed everyday decisions about their healthcare should be left to health professionals. Conversely this means that $78 \%$ of the sample wanted ownership of these decisions. It must be conceded that in situations requiring major decisions about treatment, $75 \%$ of older 
people in the same study chose to defer to health professionals and $50 \%$ said they would cooperate even when they disagreed. But none of this forms a solid basis on which to dismiss concordance as impractical in the nursing care of older people. More than any other living birth cohort people over 65 years old have witnessed paternalistic practice in an age which predates the questioning of authority as a societal norm (Heath, 1999). This being the case it is surprising that the number of old folk opting to surrender their autonomy is not greater than these figures imply. Moreover electing to delegate decision making to others is quite different from being denied participation in the first place (Hook, 2006).

In a literature review of medicine taking habits among older people, Westbury (2003) found that professional concerns about concordance were often unfounded and that in many cases prescribed regimens were better sustained by older people than in younger groups. Banning (2004) confirms this arguing that older people desist from adhering to care plans for the same practical, economical, logistical, social and belief reasons as the rest of the us. It is interesting that much polypharmacy among older people has been found to exist in nursing homes where paternalistic models of medicine management are still in place and residents were not involved in the review or evaluation of their treatment profiles (Furniss, 2002). This would suggest that problems with medicines management arise where older people are not offered choice rather than where they are.

It seems that insufficient attention is given to the individual perspective of the older person and how this shapes their health and healthcare behaviours. Snowden (2008:118) calls for ' individual tailored approaches' to prescribing practice with older people but it is difficult to ascertain how this can be achieved while the practitioner 
still views patient knowledge as secondary to their own (Hemingway and Snowden,2012).

Older people have opinions and values fuelled by long life experience. Some of their perspectives may be punctuated with misinformed values and prejudices but in this they are no different from other sections of the population including the nurses who care for them. Phair (1999) argues stereotyping of older people means that their behaviour is often misinterpreted negatively because their intentions are misunderstood. It may be that we have stopped listening or worse still forgotten to ask the salient questions.

For the birth cohorts currently in their seventies, eighties and nineties, life has been more about survival and endurance than the self fulfilment and development envisaged by those born after World War Two. Illness and disease together with the hardship they bring are viewed as a natural part of life instead of the barrier to growth and prosperity envisaged by younger generations (Antikainen et al, 1996; Heath, 1999). This has implications for health and medication management. Habraken et al (2008) describe how many patients with Chronic Obstructive Pulmonary Disorder conceal the difficulties they experience with the condition because they perceive them to be part of the normal lived experience of being old, only seeking professional intervention in response to an acute exacerbation. This carries strong echoes of Cornwell's research findings (1983) of over thirty years ago in which old people were found to understate their health and social problems for fear of being a burden to their carers.

It would seem that as with other groups, successful nursing interventions with older people require exploration and acknowledgement of the patient's values, motives, concerns and personal situated understanding to partner professional expertise in 
informing and securing effective care planning. However, McCormack (2003) points out that because nursing intervention with older people often occurs at times of crisis (eg: illness, bereavement, exploring options in residential care) when the patients powers of adaption may be at a low ebb, open questions aimed at seeking an older person's wishes may not meet with success. Instead McCormack (2003) stresses the place of biography in person centred care with older people. When the patient is permitted to tell stories about their life, the nurse is able to own a clearer picture of the context of the patient's values and preferences. Any questions which follow can be more precise and easier for the patient to answer.

The findings of a randomised controlled trial conducted by Higgins, Livingston and Katona (2004) works to oppose the idea that concordance cannot be measured. Nineteen patients over the age of 65 years diagnosed with depression and on a new prescription of antidepressants within the previous two weeks were divided into a control group of 9 who received standard treatment and an intervention group of 10 who received cognitive behavioural therapy in relation to taking antidepressants. At one month and three months the medicine regimen was sustained and there was a more positive belief among the intervention group about the efficacy of antidepressants. Interestingly this belief was not held in relation to other medicines. Quality of life (measured using a 12 item health status questionnaire) and freedom from depressive symptoms (measured using the Hamilton Rating Scale) was greater among the intervention group at one and three months. The study shows that the role of social and psychological engagement would appear vital to sustaining concordance especially with patients prone to isolation and stereotyping. 
The experience of innovative practice (Martin and Younger, 2000 ;Shumaker, Ockene and Riekert, 2009) suggests that even where degrees of cognitive impairment exist, the use of aide memoirs, decision making aids dispensing kits and the representation of the older persons wishes through the involvement of family in care planning, framing of the patient's views within living wills and advanced medical directives means that service user empowerment can continue after decision making capacity is lost. In this there is some overlap with the final setting to be considered: mental health.

\section{Concordance in the Mental Health Patient}

The viability of concordance in mental health practice has invited passionate debate (Hemingway and Snowden, 2012). Vuckovich (2010) expresses anxiety over the ethical dilemma arising from the obligation to form therapeutic alliances with patients suffering from mental illness. Claiming an essential role of involuntary treatment for some patients who are a threat to others as well as themselves, she argues that severe psychotic illness requires professional control of some patients' disease management.

On initial examination the obstacles to partnership working in the face of severe mental illness would seem insurmountable. Shared decision making requires the patient to share their description of their illness experience and to consider the perspective of the nurse. But there are metacognitive difficulties common to schizophrenia which means that this is problematic. For such patients judgement is distorted by delusions and hallucinations. As a consequence of this their insight into their illness and its impact on their lives is disabled (Lysaker et al,2011). A fractured ability to distinguish between their thoughts and those of others means that people suffering from psychotic illness often cannot empathise or take on board the views of 
others. This struggle with interpersonal perspective taking is mirrored by an inability to perceive their own sense of agency in their lives. Without a sense of agency there is no understanding of a need to master or take responsibility for the self (Chan and Mak, 2012). Psychosis also derails cognitive integrity resulting in disordered and impoverished speech coupled with difficulty in decoding the diverse landscape of the vernacular; the pragmatic use of language including metaphors, hints, humour and intentions of others (Chan and Mak, 2012).

However these barriers to concordance in mental illness must be placed against the opportunities to negotiate them and the viability of the alternatives. People with Schizophrenia show a higher level of interest in care plan participation than other groups but report lower involvement in their care amid less effective rates of medicine taking (Curtis et al, 2010). Furthermore participation by mental health patients has leaned towards treatment at the expense of discussion on social issues such as employment, housing and personal relationships despite the relevance of these issues to recovery (Chan and Mak, 2012).

The role of organismic valuing; the inner sense of self worth inherent in a concordant relationship has increased salience in mental illness. This is because care and care planning can only progress in a context of trust in which the patient can be helped to navigate and test reality against many fears anxieties and delusions. A phenomenological study by Shattell et al (2007) of twenty community patients with mental illness yielded findings which fly in the face of many preconceived notions of need in mental health practice. Patients sought a stable calming consistent force in their carers. Personal warmth and touch together with the ability to supply reassurance and share personal perspectives were all highly prized. Listening was 
seen as a skill in its own right separate from care planning and solution finding. This research suggested mentally ill people are ready to reach out to their nurses and work with them.

The danger that many service users with mental illness can be harmful to themselves and others has led to many fears and anxieties and caused many to argue that there is a sustainable place for paternalism. But duty of care alone will not lead to a sustainable recovery when mental health is built on being able to have control over one's own life. A balanced therapeutic relationship has been shown to improve health outcomes and prolong recovery (Curtis et al, 2010). Far from being undermined by the severity of psychotic illness shared decision making may be crucial.

Even during the most serious phases of schizophrenia a path to concordance can be prepared. Poor insight need not prevent this if the patient's own narrative on how they see their world can be sought and heard. In doing so a relationship of trust can be built on which other activities which will encourage patient independence can be arranged (Chan and Mak, 2012). Windows of health as opportunities to improve the patient's thought processes can be exploited by sharing 'bite sized' pieces of information tailored to coping levels of the patient which in turn will help repair the art of conversation (Kennedy, 2007). As progress is made the amount of information shared and the length of the conversation can be increased. Practicing conversation in planning small tasks will in turn help restore pragmatic language deficits (Chan and Mak, 2012). As with other patient groups, simple decision making aids such as the use of colour charts together with seeking to clarify patient preferences with 
family and relatives will also help the patient progress toward a position of concordance (Simmons et al, 2010).

\section{Recommendations for Practice}

In clinical areas where partnership working may have previously been viewed as impractical, concordance will only become a reality when its meaning is embedded in policy and documentation as well as practice learning and guidance. For children's nursing this means that child friendly booklets, leaflets, posters and apps on health living, admission, consultation and discharge should be designed and made available as part of working with children. A full range of age appropriate play materials should be used to reinforce the meaning of care. The structure of child care records and care plans should have an integral 'concordance pathway' with examples provided of how nursing interventions can be explained to children of different ages using a range of resources. Care plans should also have separate spaces for the separate concerns of children and their parents together with the nursing response. The parents' role as intermediary should continue to be valued but never at the exclusion of the child. Parents who are anxious that their child may be exposed to too much information may give some ground when it is explained that total exclusion from discussion and decision making may also cause their child anxiety.

In the care of older people care plans need to be built on nursing knowledge of patient biography. Time and space need to be reserved for the sharing of life stories as a tool to contextualise patient perspectives and inform care planning. Care plans 
should also reflect the perspectives of the patients' family and draw on living wills and advanced directives where decision making capacity has deteriorated.

In mental health, care plans for patients suffering from hallucinations and delusions should begin with the patient's narrative. Charts or tables could provide a means of measuring progress through a series of negotiated small tasks aimed at restoring coherent language and trust of surroundings en route to shared decision making.

Children, Older People and Patients suffering from mental illness will need special consideration in terms of communication and information sharing styles. An approach which works with one group may not work with another. Children will appreciate eye level conversation pitched at their level of understanding. Older people will value the time taken to become acquainted with them and their biographies. Mentally ill patients will welcome small sensitive and supportive steps toward a greater say in their care. Concordance possibilities should be taught and discussed in undergraduate and post graduate nurse education across all branches through use of case scenarios. Patients and relatives should number among the stakeholders in planning task and finish groups allowing service users to play their part in forging best practice.

\section{Conclusion}

Concordance is an open ended relationship between patient and practitioner where different perspectives and knowledge sources can be shared and challenged without loss of face fuelling and reshaping a sustainable care plan. Altered decision making capacity is the norm across every stage of the lifespan. As such the viability of concordance and related improved outcomes with children, older people and people 
suffering from mental illness is linked to the commitment of the nurses to the concept and its underpinning values. Good practice should recognise the importance of exploiting windows of improved health as points of negotiation with patients. Good practice will also value structured discussion with a patient's family, living wills and directives. The propensity for paternalism that still features in some areas of nursing would suggest that there is danger in allowing patients to make their own decisions because at times it will inevitably result in error. But error is a feature of the human condition tied up with our autonomy and inability to foresee the future. Paternalism cannot change that. Pursuing concordance can change the effectiveness of our practice for the better by helping patients at every point in their lives to take responsibility for their own health. A relationship of mutual respect will mean they will act on our advice when they believe it is right for them. They will also appreciate our support when plans go awry and we will often find that we learn much from them. Concordance is less of a leap in the dark and much more a road with no viable alternative.

\section{References}

Antikainen,A, Houtsonen, J, Kauppila, J, and Turunen,A.(1996) Living in a Learning Society: Life Histories, Identities and Education. London. Falmer

Banning, M (2004) Enhancing Concordance with Prescribed Medication in Older People. Nursing Older People. 16 (1):14-17

Bowskill, D, Garner, L. (2012) Medicines non- adherence: adult literacy and implications for practice. British Journal of Nursing. 21(19):1156-59

Chan KKS, Mak, WWS (2012) Shared decision making in the recovery of people with schizophrenia: The role of metacognitive capacities in insight and pragmatic language use. Clinical Psychology Review. 32 (2012) 535-544

Children Act (1989) HMSO, London.

Children Act (2004) HMSO, London. 
Cribb, A,. Entwhistle VA. (2011) Shared Decision Making: trade offs between narrower and broader conceptions. Health Expectations, 14(2):210-219

Cornwell, J. (1983) Hard Earned Lives. London :Tanstode.

Coulter, A, Collins A, (2011) Making Shared Decision Making a Reality: no decision about me without me. London. The Kings Fund.

Curtis LC, Wells, SM, Penney, D, Ghose, SS, Mistler, LA, Mahone, IH, DelphineRittman, M, del Vecchio, P and Lesko, S. (2010) Pushing the Envelope: Shared Decision Making in Mental Health. Psychiatric Rehabilitation Journal. 34(1) 14-22

Department of Health (2001) Good Practice in Consent. London. The Stationery Office.

Furniss, I.(2002) Use of Medicines in Nursing Homes for Older People. Advances in Psychiatric Treatment 8(3):198-204

Gabe, J, Olumide, G and Bury, M. (2004) 'It takes three to tango': a framework for understanding patient partnership in paediatric clinics', Social Science and Medicine 59(5): 1071-1079

Habraken, J.M., Pols, J., Bindels, P.J.E. and Willems, D.L. (2008) The Silence of Patients with end-stage COPD: a qualitative study. British Journal of General Practice ,58(557): 844-849

Heath, H. (1999) Perspectives on Ageing and Older People. In: Heath and Scofield (Eds) Healthy Aging: Nursing Older People. London. Mosby:3-20

Hemingway, S and Snowden A. (2012) Debating mental health nurses role on medicines management. British Journal of Nursing, 21(20):1219-1223.

Higgins, N, Livingstone, G, Katona, C (2004) Concordance Therapy: an intervention to help older people take antidepressants. Journal of Affective Disorders. 81( 3):287291

Hook, M.L. (2006) Partnering with patients - a concept ready for action. Journal of Advanced Nursing 56(2), 133-143

Kennedy, S.(2007) The Mental Health Perspective. In: McKinnon.(Ed) Towards Prescribing Practice. Chichester. Wiley :223-260

Kilkelly, U. Donnelly, M (2006) The Rights of the Child to be Heard in the Healthcare Setting: views of children parents and health professionals. Dublin. Office of the Minister for Children.

Leach, P.(2000) Children First, what we are not doing and should be doing for children today. Second Edition. London Michael Joseph

Lysaker, P. H., Dimaggio, G., Buck, K. D., Callaway, S. S., Salvatore, G., Carcione, A., and Stanghellini, G. (2011). Poor insight in schizophrenia: Links between different 
forms of metacognition with awareness of symptoms, treatment needed, and consequences of illness. Comprehensive Psychiatry, 52,(3): 253-260.

Martin, G, Younger, D. (2000) 'Anti-Oppressive Practice, a route to the empowerment of people with dementia through communication and choice.' Journal of Psychiatric and Mental Health Nursing., 7(1):59-67

Mason, J, Fattore, T (eds) (2005) Taking Children Seriously, in theory, policy and practice. London Jessica Kingsley

McCormack, B. (2003) A conceptual framework for person-centred practice with older people. International Journal of Nursing Practice. 9(3): 202-209

McKlinDon, DD, Schlucter, J.(2004) Parent and Nurse Partnerships for Therapeutic Relationships. Pediatric Nursing 30(5): 418- 20

McKinnon, J.(2013) The Case for Concordance: value and application in nursing practice. British Journal of Nursing. 22(13):766-771

Mill, JS (1859) On Liberty. London. Longmans, Roberts and Green

Office of the Public Guardian(2007) Mental Health Capacity Act 2005 Code of Practice. Norwich. The Stationery Office.

Phair, L. (1999) Mental Health. In: Heath and Scofield (Eds) Healthy Aging: Nursing Older People. London. Mosby:407- 433.

Sanz, E. (2003) Concordance and children's use of medicines. British Medical Journal 327(7419):858-860

Save the Children (2009) Never too Young: How young children can take responsibility and make decisions. London. Save the Children.

Shattell, M, M., Starr, S.S., Thomas, S.P., (2007) 'Take my hand, help me out': Mental health service recipients' experience of the therapeutic relationship. International Journal of Mental Health Nursing. 16, 274-284

Shier,H.(2001) Pathways to participation: openings, opportunities and obligations. Children and Society.15(2):107-117

Shumaker, S., Ockene, J. and Riekert, K. (2009) The handbook of health behaviour change. New York. Springer Publishing Company.

Simmons, M, Hetrick, S. and Jorm, A (2010) Shared Decision Making: benefits, barriers and current opportunities for application. Australasian Psychiatry 18(5): 394397

Snowden, A (2007) Medication Management in older adults: a critique of concordance. British Journal of Nursing. 17(2):114-119 
Tates, K., Meeuwesen, L., Elbers, E. and Bensing, J. (2002) ' "I've come for his throat": Roles and identities in doctor-parent-child communication', Child: Care, Health \& Development 28, 109-16

Treseder, P. (2004) Empowering Children and Young People: Promoting Involvement in Decision Making. London. Save the Children

UN (1989) Convention on the Rights of the Child. Geneva: United Nations Office of the High Commissioner for Human Rights.

Vuckovich PK (2010) Compliance versus adherence in serious and persistent mental illness. Nursing Ethics. 17(1): 77-85

Webb,E.(2004) Discrimination against children. Archives of Disease in Childhood. 89 (9):804-808.

Westbury, J.(2003) Why do older people not always take their medicines? Pharmaceutical Journal. 271(7270):493

Williams, A., Noyes, J. (2009) The Information Matters Project: health, medicines and self-care choices made by children, young people and their families: information to support decision-making. Study protocol. Journal of Advanced Nursing. 65 (9): 1807- 1816

Williams, A. and Noyes, J. (Joint PIs), Chandler-Oatts, J., Allen, D., Brocklehurst, P., Carter, C., Gregory, J., Lenton, S, Lewis, M., Lowes, L., Threadgold, T. (2011) Children's Health Information Matters: Researching the practice of and requirements for age appropriate health information for children and young people. Final Report. London. NIHR Service Delivery and Organisation programme

World Health Organization (1986) The Ottawa Charter for Health Promotion. WHO. Geneva.

\section{Pursuing Concordance in Challenging Settings: Main Points}

- Concordance is best viewed as an open ended relationship in which nurse and patient can respectfully challenge each other on the basis of empirical and social evidence en route to planning care.

- Altered decision making capacity is the rule rather than the exception across the life span for all patients.

- Achieving concordance in challenging settings hinges on negotiation pitched at a level that is appropriate for patient understanding.

- Children, the mentally ill and older people all have greater capacity for shared decision making than is generally believed.

- Parents, Children, Partners and Carers can all positively contribute to a concordant relationship. 


\section{Figure One Shier's Model of Participation for Children Pathways to Participation}

\begin{tabular}{|c|c|c|c|}
\hline & OPENINGS & OPPORTUNITIES & OBLIGATIONS \\
\hline $\begin{array}{l}\text { 5: Children } \\
\text { share power \& } \\
\text { responsibility } \\
\text { for decision }\end{array}$ & $\begin{array}{l}\text { Are you ready to } \\
\text { share some of } \\
\text { your adult power } \\
\text { with children? }\end{array}$ & $\begin{array}{c}\text { Is there a procedure } \\
\text { that enables children } \\
\text { to share power and } \\
\text { responsibility for } \\
\text { decisions? }\end{array}$ & $\begin{array}{l}\text { Is it a policy } \\
\text { requirement that } \\
\text { children and adults } \\
\text { share power and } \\
\text { responsibility for } \\
\text { decisions? }\end{array}$ \\
\hline $\begin{array}{l}\text { 4: Children are } \\
\text { involved in the } \\
\text { decision } \\
\text { making } \\
\text { process }\end{array}$ & $\begin{array}{l}\text { Are you ready to let } \\
\text { children join in your } \\
\text { decision-making } \\
\text { processes? }\end{array}$ & $\begin{array}{l}\text { Is there a procedure } \\
\text { that enables children } \\
\text { to join in decision- } \\
\text { making processes? }\end{array}$ & $\begin{array}{l}\text { Is it a policy } \\
\text { requirement that } \\
\text { children must be } \\
\text { involved in decision- } \\
\text { making processes? }\end{array}$ \\
\hline
\end{tabular}

\begin{tabular}{|c|c|c|c|}
\hline $\begin{array}{l}3: \text { Children's } \\
\text { views taken } \\
\text { into account }\end{array}$ & $\begin{array}{l}\text { Are you ready to } \\
\text { take children's } \\
\text { views into } \\
\text { account? }\end{array}$ & $\begin{array}{l}\text { Does your decision } \\
\text { making process } \\
\text { enable you to take } \\
\text { children's views into } \\
\text { account? }\end{array}$ & $\begin{array}{l}\text { Does policy state } \\
\text { that children's } \\
\text { views be given due } \\
\text { weight in decision } \\
\text { making? }\end{array}$ \\
\hline $\begin{array}{l}\text { 2: Children are } \\
\text { supported in } \\
\text { expressing } \\
\text { their views. }\end{array}$ & $\begin{array}{c}\text { Are you ready to } \\
\text { support children } \\
\text { in expressing } \\
\text { their views? }\end{array}$ & $\begin{array}{c}\text { Do you have a range } \\
\text { of ideas and } \\
\text { activities to help } \\
\text { children express } \\
\text { their views? }\end{array}$ & $\begin{array}{l}\text { Is it a policy } \\
\text { requirement that } \\
\text { children must be } \\
\text { supported in } \\
\text { expressing their } \\
\text { views? }\end{array}$ \\
\hline $\begin{array}{l}\text { 1: Children are } \\
\text { listened to }\end{array}$ & $\begin{array}{l}\text { Are you ready to } \\
\text { listen to }\end{array}$ & $\begin{array}{c}\text { Do you work in a } \\
\text { way that enables } \\
\text { you to listen to } \\
\text { children? }\end{array}$ & $\begin{array}{l}\text { Is it a policy } \\
\text { requirement that } \\
\text { children must be } \\
\text { listened to? }\end{array}$ \\
\hline
\end{tabular}

- Unicef Threshold 


\section{A.Shier (2001) "Pathways to Participation: Openings, Opportunities} and Obligations," Children and Society 15(2): 107-117.

\section{Figure Two: Treseder's Model of Participation}

Treseder, P. (2004) Empowering Children and Young People: Promoting Involvement in Decision Making. London. Save the Children

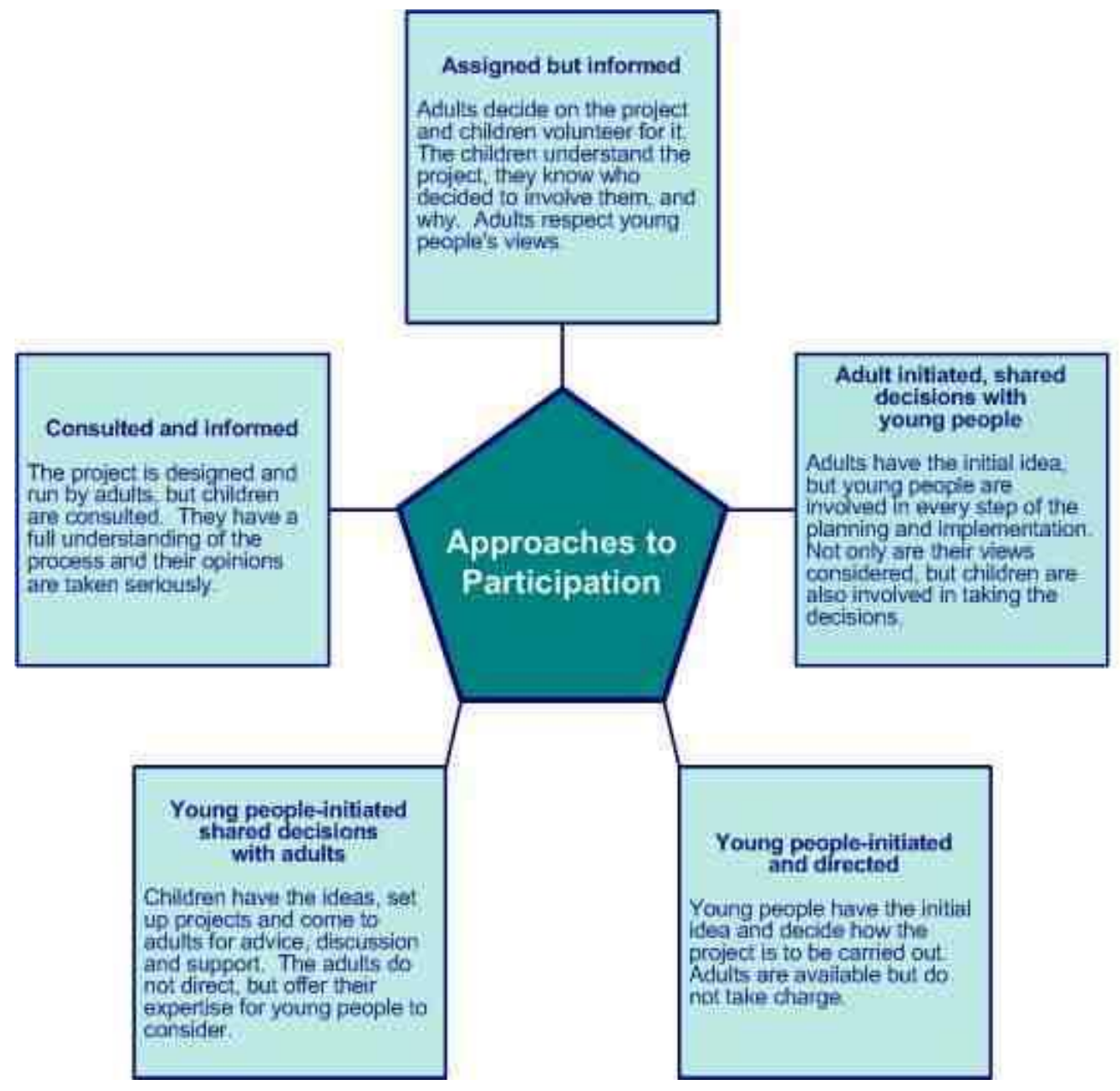

